\title{
Prevalence of Autism/ASD Among Preschool and School-age Children in Norway
}

\author{
Kamil Özerk $^{1}$ - Donald Cardinal ${ }^{2}$ \\ Published online: 8 July 2020 \\ (C) The Author(s) 2020
}

\begin{abstract}
In recent years, there has been a considerable rise in prevalence rates for autism/autism spectrum disorders (ASD) around the globe. Understanding the patterns of prevalence is essential for policy development at national and local levels that effectively plans for medical, psychological, behavior analytical, and educational interventions. This study presents new data on the prevalence of ASD among preschool and school-age children (ages 1-16 years) in Norway. Based on the International Classification of Diseases (ICD-10) criteria for diagnosis, the rate of ASD increased from 2014 to 2016. The study found a much higher increase in prevalence rate among preschool-age (1-5 years) children than school-age (6-16 years) children over the same 2-year period. At the same time, however, the rate of ASD among school-age children (6-16) compared with that among preschool children (1-5) is higher in 2014 and 2016, indicating a school-age effect. The results also indicate a shifting pattern of gender difference in diagnosed preschool-age children. The male-to-female ratio receiving an ASD diagnosis has increased from 4.46:1 in 2014 to 4.57:1 in 2016, suggesting that the gender gap may be slightly widening for preschool children. For school-age children, the gender gap (male-to-female ratio) is slightly narrowing, moving from 3.53:1 in 2014 to 3.46:1 in 2016. While these changes may not seem significant, the implications of the full findings are discussed.
\end{abstract}

Keywords Autism spectrum disorder · Diagnosis · Prevalence · Preschool children · School-age children · School-age effect · Norway

\section{Introduction}

Autism is a developmental disability that affects how a person communicates with and relates to other people, as well as how that person experiences the world around them (National Autistic Society 2018). Autism and related disorders comprise the autism spectrum disorders (ASD). Children with autism/ ASD have varying levels of difficulties with social behavior and communication, have limited interests, and engage in restricted and repetitive behaviors. The course of ASD symptoms appears to be lifelong for the majority of cases. These challenges with social communication, behavior, and social

Kamil Özerk

Kamil.Ozerk@iped.uio.no

1 Department of Education, Faculty of Educational Sciences, University of Oslo, Sem Sælandsvei 7, 0317 Oslo, Norway

2 Attallah College of Educational Studies, Thompson Policy Institute (TPI) on Disability and Autism, Chapman University, 1 University Dr, Orange, CA 92866, USA interaction often co-occur with other disorders such as attention deficit hyperactivity disorder, intellectual disorder, and epilepsy, making it difficult for many persons with autism/ ASD to live independently (Matson and Kozlowski 2011). ASD is, therefore, considered a complex developmental disability.

Prevalence studies in many countries during previous decades (Elsabbagh et al. 2012; Özerk 2016) show that there has been a considerable rise in the prevalence rates for autism/ ASD around the globe. Given these increases, educational and health care authorities need to be informed about the prevalence of autism/ASD in their jurisdictions. Such data is essential for policy developers at the local and national levels to properly plan for medical, psychological, behavioral, and educational interventions (Cardinal and Fraumeni-McBride 2017; Isaksen et al. 2012; Özerk 2014; Williams et al. 2008). Research shows that early intensive behavioral interventions based on evidence-based practices for young children with autism/ASD can enhance developmental outcomes (Eikeseth et al. 2007; Eldevik et al. 2009; Warren et al. 2011; Wong et al., 2015). 


\section{International Prevalence of Autism/ASD}

Studies in different areas of the USA during the period 20002016 showed a considerable increase in prevalence rates for autism/ASD among 8-year-old children. In 2000, the prevalence rate among 8-year-olds was 1 in 150. In 2012, the estimated prevalence of autism/ASD among 8-year-olds increased dramatically to 1 in 68 (Blumberg et al. 2013; Christiansen et al. 2016; Zablotsky et al. 2015), then 1 in 59 in 2014 (Baio et al. 2018). The prevalence increased again in 2016 to 1 in 54 in 2016 (Maenner et al., 2020). Furthermore, there are considerable geographical differences in prevalence rates among states and even among different counties or regions in the same state or county (Elsabbagh et al. 2012; Özerk 2016; Baio et al. 2018; Maenner et al. 2020).

Studies of the prevalence of autism/ASD in different countries (see Table 1) illustrate apparent differences in prevalence rates. This can be attributed to differences in data gathered from different age groups and different geographical areas and using varying research methodologies, differences in accessibility to expertise, and more. Sometimes, the differences are due to inclusion criteria (in some studies, all of the disorders under spectrum (ICD-10: F84.0-F84.9) are included; in other studies, only one of the subcategories of pervasive developmental disorders (F84.0 Childhood autism) is included) (Özerk 2016). Even with these factors in mind, the overall trend in the studies conducted during the last two decades is that the prevalence of autism/ASD is increasing among children and young adults globally.

Table 1 shows representative prevalence studies from different countries.

In addition to American studies, the other studies presented in Table 1 reveal high rates of prevalence of autism/ASD particularly the Israeli study by Davidovitch et al. (2013), the study by Roelfsema et al. (2012) in the Netherlands, and three Swedish studies (Gilberg et al. 2006; Idring et al. 2012; Sandin et al. 2014). These studies each show higher rates of prevalence in their respective countries than earlier studies (Elsabbagh et al. 2012; Özerk 2016). As we will discuss in the following sections, a comparison of prevalence among preschool-age children versus school-age children will highlight a school-age effect on the prevalence of autism/ASD.

\section{School-age Effect on Prevalence of Autism/ASD}

We use the term school-age effect to denote the higher prevalence rates among school-age children compared with preschool-age children. As Table 1 shows, the study conducted by Green et al. (2004) in the UK presents that the prevalence rate of autism/ASD among 5- to 16-year-old British children is quite high. Specifically, 1 in 111 school-age children has received a diagnosis of autism/ASD. The highest prevalence rate is found among the subgroup of schoolchildren of 5 to 10 years of age. In this group, 1 in 100 children was diagnosed with autism/ASD. In two British regional studies (Baird et al. 2006; Baron-Cohen et al. 2009), the rate of autism/ASD among school-age children (5 to 9 years old) is higher than that in preschool-age children ( 1 to 5 years old). A similar trend can also be seen in Japanese studies (Honda et al. 2005; Kawamura et al. 2008). The Australian study by Williams et al. (2008) also shows what we call the school-age effect, while the prevalence rate of autism/ASD among preschoolers ( 0 to 5 years old) is 1 in 455 , the rate increases considerably to 1 in 160 among school-age children (6- to 12-year-olds). A similar ascending trend is seen in the Canadian longitudinal study (OuelletteKuntz et al. 2012). In 2003, the rate was 1 in 300 among preschoolers ( 2 to 4 years old) and 1 in 189 among schoolage children (5 to 14 years old). In 2008, the rate of autism/ ASD increased to 1 in 159 among preschoolers and to 1 in 101 among school-age children. The Danish nationwide study (Parner et al. 2008) of prevalence rates shows a rise among school beginners (5.9 years old and 5.8 years old) compared with younger children (5.3 years old). As one can see in Table 1, there is a $57 \%$ increase in the prevalence rate among Danish school-age children (6 to 11 years old) compared with preschoolers (3 to 5 years old): from 1 in 621 to 1 in 395 .

\section{Prevalence of Autism/ASD and Gender Differences}

A comprehensive meta-analysis of 54 prevalence studies conducted by Loomes et al. (2017) mentions the well-known male-to-female ratio of 4:1, though they claim that the gender gap is less than this. One of the arguments in their study is that the characteristics of autism in males differ from autism characteristics in females. Compared with males, the likelihood of females with autism showing "limited interests" is less; thus, females are often underrepresented in prevalence rates. Another factor is that females appear to be better at camouflaging their autism-related difficulties, which makes their diagnosis more difficult. A third factor potentially contributing to what the researchers call the diagnostic bias is that the key people involved in children's lives, including parents, referral (parents, teachers, school counselors, and school psychologists), and other professionals, have preconceived notions that autism/ASD is a male disorder, thereby reducing their sensitivity to autism symptoms in females.

Finally, Loomes et al. (2017) further argue that a disproportionately high number of females who exhibit autistic traits when using different observational instruments do not meet the autism/ASD criteria in DSM or ICD. They argue that this is because the criteria lack sensitivity to the autistic traits found particularly in females, such as social communication 
Table 1 International studies on prevalence of autism/ASD

\begin{tabular}{|c|c|c|c|c|c|c|}
\hline Research & Country & Data source & $\begin{array}{l}\text { Geographic } \\
\text { level }\end{array}$ & Age group & Year & $\begin{array}{l}\text { Prevalence } \\
\text { rate }\end{array}$ \\
\hline $\begin{array}{l}\text { Blumberg et al. (2013) } \\
\text { Christensen et al. (2018) } \\
\text { Zablotsky et al. (2015) }\end{array}$ & $\begin{array}{l}\text { USA } \\
\text { USA }\end{array}$ & $\begin{array}{l}\text { Estimates based on } \\
11 \text { representative } \\
\text { sites }\end{array}$ & Nationwide & $\begin{array}{c}8 \text { years } \\
\text { old }\end{array}$ & 2012 & 1 in 68 \\
\hline Baio et al. (2018) & USA & $\begin{array}{l}\text { Estimates based on } \\
11 \text { representative } \\
\text { sites }\end{array}$ & Nationwide & $\begin{array}{c}8 \text { years } \\
\text { old }\end{array}$ & 2014 & 1 in 59 \\
\hline Maenner et al. (2020) & USA & $\begin{array}{l}\text { Estimates based on } \\
11 \text { representative } \\
\text { sites }\end{array}$ & Nationwide & $\begin{array}{c}8 \text { years } \\
\text { old }\end{array}$ & 2016 & 1 in 54 \\
\hline $\begin{array}{l}\text { Cardinal and Fraumeni-McBride } \\
\text { (2017) }\end{array}$ & CA, USA & Official registries & Statewide & $3-22$ & 2014 & 1 in 69 \\
\hline $\begin{array}{l}\text { Cardinal and Fraumeni-McBride } \\
\text { (2017) }\end{array}$ & Orange, CA, USA & Official registry & Countywide & $3-22$ & 2014 & 1 in 50 \\
\hline Davidovitch et al. (2013) & Israel & Official registries & Countrywide & $1-12$ & $\begin{array}{l}2004 \\
2010\end{array}$ & $\begin{array}{l}1 \text { in } 1533 \\
1 \text { in } 196\end{array}$ \\
\hline \multirow[t]{3}{*}{ Roelfsema et al. (2012) } & $\begin{array}{l}\text { Eindhoven, } \\
\text { The Netherlands }\end{array}$ & Official registry & Regional & $4-14$ & 2012 & 1 in 44 \\
\hline & Haarlem, The Netherlands & Official registry & Regional & $4-14$ & 2012 & 1 in 199 \\
\hline & Utrecht, The Netherlands & Official registry & Regional & $4-14$ & 2012 & 1 in 175 \\
\hline Idring et al. (2012) & Sweden & Official Registry & Nationwide & $0-17$ & 2012 & 1 in 87 \\
\hline Sandin et al. (2014) & Sweden & Official Registry & Nationwide & $3-15$ & 2014 & 1 in 141 \\
\hline Gilberg et al. (2006) & Göteborg, Sweden & Official Registry & Citywide & $7-12$ & 2001 & 1 in 124 \\
\hline Green et al. (2004) & UK & Official Registry & Nationwide & $\begin{array}{l}5-10 \\
5-16\end{array}$ & $\begin{array}{l}2004 \\
2004\end{array}$ & $\begin{array}{l}1 \text { in } 100 \\
1 \text { in } 111\end{array}$ \\
\hline Baird et al. (2006) & West Midland, UK & Official Registry & Regional & $1-5$ & 2006 & 1 in 409 \\
\hline Baron-Cohen et al. (2009) & Cambridgeshire, UK & Official Registry & Regional & $5-9$ & 2009 & 1 in 64 \\
\hline Honda et al. (2005) & Yokohama City, Japan & Official Registry & Citywide & 5 & 2005 & 1 in 266 \\
\hline Kawamura et al. (2008) & Toyota City, Japan & Official Registry & Citywide & $5-8$ & 2008 & 1 in 55 \\
\hline Williams et al. (2008) & Australia & Official Registry & Nationwide & $\begin{array}{l}0-5 \\
6-12 \\
13-16\end{array}$ & $\begin{array}{l}2005 \\
2005 \\
2005\end{array}$ & $\begin{array}{l}1 \text { in } 455 \\
1 \text { in } 160 \\
1 \text { in } 278\end{array}$ \\
\hline Quellette-Kunts et al. (2012) & Three regions, Canada & National Registry & Nationwide & $\begin{array}{l}2-4 \\
5-14 \\
2-4 \\
5-14\end{array}$ & $\begin{array}{l}2003 \\
2003 \\
2008 \\
2008\end{array}$ & $\begin{array}{l}1 \text { in } 300 \\
1 \text { in } 189 \\
1 \text { in } 159 \\
1 \text { in } 101\end{array}$ \\
\hline Parner et al. (2008) & Denmark & National Registry & Nationwide & $\begin{array}{l}5.9 \\
5.8 \\
5.3\end{array}$ & $\begin{array}{l}2008 \\
2008 \\
2008\end{array}$ & $\begin{array}{l}1 \text { in } 122 \\
1 \text { in } 135 \\
1 \text { in } 162\end{array}$ \\
\hline Lai et al. (2012) & Taiwan & Official Registry & Nationwide & $\begin{array}{l}3-5 \\
6-11\end{array}$ & $\begin{array}{l}2010 \\
2010\end{array}$ & $\begin{array}{l}1 \text { in } 621 \\
1 \text { in } 395\end{array}$ \\
\hline
\end{tabular}

difficulties, sensory-related difficulties, and difficulties with flexibility. Nevertheless, Loomes et al. (2017) point to several studies where the "gender gap" becomes narrower and claim that "Of children meeting criteria for ASD, the true male-tofemale ratio is not $4: 1$, as is often assumed; rather, it is closer to $3: 1$ " (p. 446).

\section{Purpose of the Study}

During the 1980s and 1990s, 1 in 1000 children received a diagnosis of autism/ASD in Norway (Gundersen and Hem
2005). Another nationwide prevalence study among birth to 10-year-old Norwegian children showed that 1 in 166 had a diagnosis of autism/ASD in 2010 (Stoltenberg et al. 2010) and 1 in 125 children, age 11 , were diagnosed with autism/ASD not long after (Surén et al. 2012). However, none of these earlier Norwegian studies highlighted the prevalence rates separately among preschoolers compared with all school-age children.

The purpose of the present study is to provide new data on the prevalence of autism/ASD among preschool and schoolage children in Norway in 2014 and 2016 and to discuss the educational consequences of the increasing prevalence rates 
of autism/ASD in the country. Our data include the total number of children at ages 1-16 who had received the diagnosis of autism/ASD in 2014 and 2016.

\section{Method and Data Sources}

The present study covers the prevalence of autism/ASD throughout Norway, among 1- to 16-year-old children and subgroups of 1- to 5-year-old and 6- to-16-year-old children who had a diagnosis of autism/ASD in 2014 and 2016. More specifically, our data includes those who were diagnosed with childhood autism (ICD-10's F84.0) and Asperger syndrome (ICD-10's F84.5) in 2014 and 2016. We purposefully did not include other subcategories of pervasive developmental disorders such as atypical autism, Rett's syndrome, other childhood disintegrative disorders, and other pervasive developmental disorders. This was done to ensure that the data focused on those with clear diagnoses of autism and Asperger syndrome rather than related disorders.

Norway's universal health care services are provided free of charge, and the country has a well-developed Norwegian Patient Registry (NPR). This paper draws on the data provided by the NPR (NPR, Data Document Dated 15.06.17, Nr. 17/ 2362-9), Norwegian Statistics (2014, 2016), and several local educational-psychological services. Children in Norway who are suspected of having autism/ASD are referred by family physicians (medical doctors) or educational-psychological services to child pediatric and specialist services. The children then undergo a thorough assessment by a multidisciplinary team and are assigned a final diagnosis by a child psychiatrist based on the International Classification of Diseases (ICD$10)$.

Both the use of ICD-10 for diagnoses and registration with the Norwegian National Patient Registry (NPR) at the Royal Department of Health are mandatory in Norway. The NPR contains nationwide data about diagnoses assigned by Norwegian specialist health services located in public hospitals and outpatient clinics. In addition to these public institutions, some private practicing pediatricians and child psychiatrists have agreements with the government and receive public funding to provide health care services and receive reimbursement. Both public and private health care service providers are obliged to report every case with their 11-digit personal identification number to the Norwegian Patient Registry. Therefore, the likelihood of having missing data is extremely low, even in a country with a total population of about 5.3 million (Norwegian Statistics 2016).

The raw data for this study were drawn from the NPR and included children up to 16 years of age who were registered as having a diagnosis of autism/ASD in 2014 and 2016 based on ICD-10's F84.0 Childhood autism and F84.5 Asperger syndrome criteria, as well as the child's age, gender, and county of residence. There are 19 counties in Norway. In each county, there are several different municipalities.

\section{Systematizing the Raw Data and Data Analysis}

As a rule, the NPR did not provide the number of children with autism/ASD in any age group in an administrative area (i.e., county or municipality) if the number of children was fewer than 5 but higher than 0 . In contrast, if no children were diagnosed with autism/ASD in any age group in a county or municipality in a given year, the row data from the NPR is noted as 0 . And if the number of children with a diagnosis of autism/ASD in a county or municipality in an age group in a given year is 5 , the row data notes this number. This means that if the number of children in an age group who received a diagnosis of autism/ASD in that county or municipality is 1,2, 3 , or 4 , the row data does not note any of these numbers as a means to preserve anonymity. For 2014 and 2016, there was no missing data.

In the NPR row data, the age groups are $0-5$ and $6-$ 16 years. When we calculated the total number of children in the first group, we excluded those who were younger than 1 year of age in the total population because no child receives a diagnosis of autism/ASD at so young an age.

We calculated the prevalence rates of autism/ASD by dividing the total number of children in each age group with the number of children with autism/ASD in that age group. We obtained the total number of children in each of the two age groups (1 to 5 years old group, called preschool-age children, and 6 to 16 years old group, called school-age children) from the Norwegian Statistics Norway (2014, 2015, 2016, 2017) for the respective year. Our aim in asking about row data for children 6 to 16 years of age was to determine the number of children who had a diagnosis of autism/ASD at what in Norway is referred to as basic school age.

Basic school is compulsory in Norway; it starts at the age of 6 and lasts 10 years. To ensure that the category " $6-16$ " includes the exact number of children at the 10 -year basic school, we used the education statistics from Norwegian Statistics Norway $(2013,2014,2015,2016,2017)$ for children who were 6-15 years of age. We then compared these statistics with the total number of children in the municipalities in each of the 19 counties in the country. This was necessary because children who were registered as 15 years old at the beginning of 10th grade, the last grade in basic school, become 16 years old at the end of that academic year. By operating in this manner, we had, with almost $100 \%$ certainty, the exact number of school-age children for 2014 and 2016 as the official educational statistics showed for those years. The data were systematized, coded in, and analyzed using IBM SPSS, Version 24.0 for Windows, and Excel 2016. 


\section{Results}

Table 2 presents the overall results for the nationwide prevalence of autism/ASD among 1- to 16-year-old children in Norway. The table shows that 2748 children between 1 and 16 years old in 2014 and 3157 children in the same age group in 2016 had autism/ASD (ICD-10's F84.0 Childhood autism and F84.5 Asperger syndrome). As seen in the table, the prevalence rate of autism/ASD among 1- to 16-year-olds nationwide was 1 in 340 in 2014, and 1 in 297 in 2016. This indicates a $14.9 \%$ increase in the prevalence rates from 2014 to 2016. Similar to the international trend, more males than females received a diagnosis of autism/ASD. Specifically, 1 in 220 males in 2014 and 1 in 192 males in 2016 had autism/ ASD. This is a $14.8 \%$ increase for males from 2014 to 2016.

The increase in the prevalence rates for females is $15.2 \%$ for the same period. In 2014, 1 in 797 females had autism/ ASD, while, in 2016, this rate rose to 1 to 695 . The gender ratio (male to female) was 3.80:1 in 2014 and 3.79:1 in 2016. This means that the male-to-female ratio was almost unchanged from 2014 to 2016 for the 1- to 16-year-old group as a whole. These results show that the gender gap remains the same among 1- to 16-year-old children with autism/ASD in Norway. Compared with the international 4:1 male-to-female ratio, however, the gender gap is slightly narrower for 1 - to 16-year-olds in Norway.

\section{Prevalence of Autism/ASD Among Preschool-age Compared with School-age Children}

Table 3 also illustrates the prevalence of autism/ASD among males and females at preschool-age ( 1 to 5 years old) and school-age (6 to 16 years old) children in 2016 compared with that in 2014. The results indicate that 377 of 1 - to 5-year-old Norwegian children, out of 316,409 children in this age group, had autism/ASD in 2014. The prevalence rate is 1 in 839 children at 1-5 years of age in 2014. In 2016, 551 children out of 310,725 at $1-5$ years of age had autism/ASD. The prevalence rate was, therefore, 1 in 564 in 2016. These figures show that the prevalence rate of autism/ASD among preschool-age children from 2014 to 2016 increased by $48.7 \%$ - a notable increase.

In 2014, 2371 school-age children (6-16-year-olds), out of 618,117 in this age group, had autism/ASD, whereas, in 2016, out of 628,122 school-age children, 2606 had autism/ASD. The prevalence rate for autism/ASD among school-age children was 1 in 261 in 2014 and 1 in 241 in 2016. This shows that the prevalence rate of autism/ASF among school-age children increased by 8.3 from 2014 to 2016 (Table 4).

\section{Gender and Prevalence of Autism/ASD}

Table 4 shows the prevalence of autism/ASD and the increase in the prevalence rates during a 2-year period among different age groups and genders. For the nationwide 1- to 16-year-old population, as noted earlier, the rates increased $14.5 \%$ from 2014 to 2016 . For males, it was $14.6 \%$; for females, $14.7 \%$.

The results also show that 1 in 839 Norwegian preschool children within the ages of 1-5 years old had autism/ASD in 2014. In 2016, the rates for autism/ASD among preschoolers were 1 in 564. The prevalence rate for autism/ASD among preschool-age children from 2014 to 2016 increased by $48.7 \%$. In 2014, the prevalence rate of autism/ASD among school-age children was 1 in 261, and in 2016, 1 in 241. This indicates an $8.3 \%$ increase in the prevalence rate of autism/ASD among school-age children from 2014 to 2016.
Table 2 Prevalence of autism/ ASD among 1- to 16-year-old males and females

\begin{tabular}{|c|c|c|c|c|}
\hline \multirow[b]{2}{*}{ Statistic } & \multicolumn{2}{|l|}{2014} & \multicolumn{2}{|l|}{2016} \\
\hline & $N$ & $\%$ & $N$ & $\%$ \\
\hline Total population (1- to 16 -year-olds) & 934,526 & 100.0 & 938,847 & 100.0 \\
\hline Males & 478,612 & 51.2 & 480,773 & 51.2 \\
\hline Females & 455,914 & 48.8 & 458,074 & 48.8 \\
\hline Autism/ASD population (1- to 16 -year-olds) & 2748 & 100.0 & 3157 & 100.0 \\
\hline Males & 2176 & 79.18 & 2498 & 79.13 \\
\hline Females & 572 & 20.82 & 659 & 20.87 \\
\hline Rates of autism/ASD (1- to 16-year-olds) & 1 in 320 & & 1 in 297 & \\
\hline Males & 1 in 220 & & 1 in 192 & \\
\hline Females & 1 in 797 & & 1 in 695 & \\
\hline Increase in rates (1- to 16-year-olds) from 2014 to 2016 & $14.9 \%$ & & & \\
\hline Males & $14.8 \%$ & & & \\
\hline Females & $15.2 \%$ & & & \\
\hline Gender ratio (males:females) & $3.80: 1$ & & $3.79: 1$ & \\
\hline
\end{tabular}


Table 3 Prevalence of autism/ ASD among males and females in preschool age and school age

\begin{tabular}{|c|c|c|c|c|}
\hline \multirow[b]{2}{*}{ Statistic } & \multicolumn{2}{|l|}{2014} & \multicolumn{2}{|l|}{2016} \\
\hline & $N$ & $\%$ & $N$ & $\%$ \\
\hline Total population (1- to 5-year-olds) & 316,409 & 100.0 & 310,725 & 100.0 \\
\hline Males & 162,546 & 51.4 & 159,334 & 51.3 \\
\hline Females & 153,863 & 48.6 & 151,391 & 48.7 \\
\hline Autism/ASD population (1- to 5-year-olds) & 377 & 100.0 & 551 & 100.0 \\
\hline Males & 311 & 82.5 & 456 & 82.7 \\
\hline Females & 66 & 17.5 & 95 & 17.3 \\
\hline Rates of autism/ASD (all 1- to 5-year-olds) & 1 in 839 & & 1 in 564 & \\
\hline Total population (6- to 16 -year-olds) & 618,117 & 100.0 & 628,122 & 100 \\
\hline Males & 316,066 & 51.1 & 321,439 & 51.2 \\
\hline Females & 302,051 & 48.9 & 306,683 & 48.8 \\
\hline Autism/ASD population (6- to 16-year-olds) & 2371 & 100.0 & 2606 & 100.0 \\
\hline Males & 1865 & 78.65 & 2042 & 64.68 \\
\hline Females & 506 & 21.35 & 564 & 35.32 \\
\hline Rates of autism/ASD (all 6- to 16-year-olds) & 1 in 261 & & 1 in 241 & \\
\hline
\end{tabular}

Preschool age includes 1- to 5-year-old children; school age includes 6- to 16-year-old children. These children were registered as 15 years old at the beginning of their last academic year (fall semester) in basic school (Norwegian Statistics, 2016)
As seen in Table 4, there is a gender difference in the prevalence rates for autism/ASD among preschool-age and school-age children. Among preschool-age males, 1 in $523 \mathrm{had}$ autism/ASD in 2014 and, in 2016, 1 in 349, indicating a $49.8 \%$ increase. In contrast, 1 in 2331 preschool-age females had autism/ASD in 2014. In 2016, the prevalence rate was 1 in 1594, indicating an increase of $46.2 \%$. The results also show that the maleto-female ratio for autism/ASD at preschool age was 4.46:1 in 2014 and 4.57:1 in 2016. More preschool-age males and more preschool-age females had autism/ASD in 2016 compared with 2014. Furthermore, when we look at the gender gap more closely, we see that among preschool children, it is slightly widening.
Among school-age (6 to 16 years old) males, 1 in 169 had autism/ASD in 2014. In 2016, the prevalence rate became 1 in 157 , indicating a $7.6 \%$ increase for males. For school-age (6 to 16 years old) females, the prevalence rate of autism/ASD is 1 in 597 for 2014, and 1 in 544 for 2016, showing a 9.7\% increase in prevalence. The male-to-female ratio is $3.53: 1$ for 2014 and 3.46:1 for 2016. Interestingly, we see an opposite tendency here compared with preschool-age children, with the gender gap narrowing for school-age children.

\section{School-age Effect for Prevalence of Autism/ASD}

As noted, the results that show an increase in the prevalence rates of autism/ASD among all of the age groups and genders
Table 4 Increase in the prevalence rates of autism/ASD for the two age groups (2014 to 2016)

\begin{tabular}{llll}
\hline Statistic & 2014 & 2016 & Increase (\%) \\
\hline Rates of autism/ASD (1- to 16-year-olds) & 1 in 340 & 1 in 297 & 14.5 \\
Males & 1 in 220 & 1 in 192 & 14.6 \\
Females & 1 in 797 & 1 in 695 & 14.7 \\
Rates of ASD (all 1- to 5-year-olds) & 1 in 839 & 1 in 564 & 48.7 \\
Males & 1 in 523 & 1 in 349 & 49.8 \\
Females & 1 in 2331 & 1 in 1594 & 46.2 \\
Gender ratio (males:females, 1- to 5-year-old) & $4.46: 1$ & $4.57: 1$ & \\
Rates of ASD (all 6- to 16-year-olds) & 1 in 261 & 1 in 241 & 8.3 \\
Males & 1 in 169 & 1 in 157 & 7.6 \\
Females & 1 in 597 & 1 in 544 & 9.7 \\
Gender ratio (males:females, 6- to 16-year-old) & $3.53: 1$ & $3.46: 1$ &
\end{tabular}


from 2014 to 2016 are not based on prevalence estimates but the actual number of officially registered children with autism/ ASD in 2014 and 2016. Table 5 compares the results between the prevalence rates of autism/ASD among school-age (6 to 16 years old) children and preschool-age (1 to 5 years old) children. These results show what we can call a school-age effect in terms of the increase in prevalence rates.

The results show that there is a likelihood that, for every preschool-age child with autism/ASD, 3.21 school-age children had a diagnosis of autism/ASD in 2014. This is equivalent to a $221 \%$ rise in prevalence rates of autism/ASD diagnoses among school-age children compared with preschoolage children in 2014. Concerning gender differences, we see that for every male of preschool age, 3.09 males of school age were diagnosed with autism/ASD in 2014. This indicates a $209 \%$ increase. For females, the increase is even more significant. For every female with a diagnosis of autism/ASD at preschool age, 3.90 females of school age were diagnosed with autism/ASD in 2014. This means that the prevalence rates for the school-age females were $290 \%$ greater than the prevalence rates for the preschool-age females in 2014.

Two years later, in 2016, the trend can be seen as similar: The likelihood of receiving a diagnosis of autism/ASD at school age compared with preschool age is higher. For every preschool-age child with autism/ASD in 2016, 2.34 schoolage children had autism/ASD. This means that $134 \%$ more school-age children had autism/ASD compared with preschool-age children. When gender differences are considered, again, we see a school-age effect. For every male of preschool age with autism/ASD, 2.22 males of school age had autism/ASD. This means that $122 \%$ more males at school age had autism/ASD compared with the males of preschool age. In contrast, for every female of preschool age with autism/ASD, there were 2.93 females of school-age autism/ ASD, indicating $193 \%$ higher rates for school-age females compared with preschool-age females in 2016.

Table 5 School-age effect for the prevalence rates of autism/ASD in 2014 and 2016

\begin{tabular}{lll}
\hline Statistic & Ratio & Increase (\%) \\
\hline $\begin{array}{l}\text { 1- to 5-year-olds in 2014 to 6- } \\
\quad \text { to 16-year-olds in 2014 }\end{array}$ & \\
All & $1: 3.21$ & 221 \\
Males & $1: 3.09$ & 209 \\
Females & $1: 3.90$ & 290 \\
1- to 5-year-olds in 2016 to 6- & & \\
$\quad$ to 16-year-olds in 2016 & & \\
All & $1: 2.34$ & 134 \\
Males & $1: 2.22$ & 122 \\
Females & $1: 2.93$ & 193 \\
\hline
\end{tabular}

These results reveal an apparent school-age effect in terms of the increase in prevalence rates of autism/ASD. A higher rate of school-age children had autism/ASD. While more males overall had autism/ASD - both in general and at school age in particular-from 2014 to 2016, an increasing number of females have been receiving a diagnosis of autism/ASD. This makes the school-age effect more visible among females compared with males. This trend also means that the gender gap in prevalence among school-age children is narrowing.

The school-age effect and narrowing gender gap among school-age children with autism/ASD from 2014 to 2016 can be seen even more clearly in Table 6 . The table provides a comparison of the prevalence rates of autism/ASD for males and females at preschool age in 2014 with the prevalence rates of autism/ASD among males and females at school age in 2016.

The table shows that the likelihood of being a school-age child with autism/ASD in 2016 is 3.48 times higher than that of children of preschool age in 2014. Furthermore, for every preschool-age male in 2014, 3.33 times more school-age males in 2016 had autism/ASD. For every preschool-age female in 2014, 4.28 times more school-age females in 2016 had autism/ASD. Most startling, however, is that the prevalence rate of autism/ASD among school-age children in 2016 is $248 \%$ greater than the prevalence rate among preschool-age children in 2014. Specifically, 233\% more males and $328 \%$ more females of school age had autism/ASD in 2016 compared with the males and females of preschool age in 2014.

These increases illuminate a school-age effect on the prevalence of autism/ASD. As noted, more males and females had autism/ASD in 2016 compared with 2014, and, as seen in Table 5, the gender difference among preschool-age children did not narrow from 2014 to 2016. The increase for preschoolage males with autism/ASD is $49.8 \%$ from 2014 to 2016, while it is $46.2 \%$ for the preschool-age females. Nevertheless, the gender gap narrowed among school-age children with autism from 2014 to 2016. For every schoolage male with autism/ASD in 2014, there were 1.08 schoolage males with the same diagnosis in 2016, for an increase of $7.6 \%$. In contrast, for every school-age female in $2014,1.10$ females in 2016 had /ASD. This shows an increase of $9.7 \%$ among school-age females compared with $7.6 \%$ among

Table 6 School-age effect for the prevalence of autism/ASD and the gender gap in 2014 and 2016

\begin{tabular}{lll}
\hline Statistic & Ratio & Increase (\%) \\
\hline 1- to 5-year-olds in 2014 to 6- & & \\
$\quad$ to 16-year-olds in 2016 & & \\
All & $1: 3.48$ & 248 \\
Males & $1: 3.33$ & 233 \\
Females & $1: 4.28$ & 328 \\
\hline
\end{tabular}


school-age males, indicating a narrowing gender gap in this age group.

Overall, there was an increase in prevalence rates in terms of both age groups and genders. Figure 1 illustrates the increase in the prevalence rates from 2014 to 2016.

\section{Discussion}

Diagnoses of autism/ASD are based on ICD-10 in Norway. Also, all incidences of autism/ASD are registered in the Norwegian Patient Registry noting gender and an 11-digit ID number. The current data on the prevalence of autism/ ASD in Norway includes 1- to 16-year-old children in 2014 and 2016. The overall results suggest that there is a higher risk of receiving a diagnosis of autism/ASD at school age than at preschool age. There may be several interrelated factors that account for this finding. Here, it is also important to mention that $92 \%$ of 1- to 5-year-old preschool-age children in Norway are enrolled in kindergartens (Statistics Norway 2017). Whether a kindergarten is public or private, it is statesubsidized in the country. All 1- to 5-year-old preschoolers are under the responsibility of educational-psychological services and public health care services, and they go through several compulsory health controls free of charge. Thus, a referral to a specialist/pediatrician is not an economic burden for any family. A typical Norwegian kindergarten for 1- to 5year-old preschoolers is predominantly play-oriented. It is worth noting the extended time for free play at the kindergartens because the symptoms and consequences of autism/ASD at this age may be easier to tolerate during play.

Furthermore, for children of this age, adults tend to take a more "wait and see" attitude compared to their views of school-age children. It is certainly possible as well that since the onset and diagnosis of autism/ASD are skewed toward the middle or even higher age range of preschool children (from among those ages 1-5), the school-age effect could be partially due to some children within the preschool group simply being unlikely candidates for such a diagnosis given their young age. As mentioned, the data used in this study from the Norwegian Patient Registry does not differentiate preschool data by individual age, only delineating the entire 1to 5-year-old range, thus not permitting an accessible analysis of the specific impact that this data format may have on our school-age effect findings.

School settings may also impact the school-age effect. Being of school-age means that children participate in more structured as well as more demanding social and academic activities, with social communication, group work, teamwork, and collaboration playing essential roles in school life. There is less tolerance for unstructured and individualistic initiatives or free play in the school-age settings. School rules include sitting behind a desk, listening to the teacher, compliance with the classroom rules, turn-taking, collective projects, class activities, and group and teamwork activities, with a sharper academic focus and cognitively demanding school language and textbooks. Also, it may be easier for a teacher at this level to compare students who are sitting in a classroom together. Thus, we can speculate that the school-age effect of increasing prevalence rates may be due to the factors embedded in the school setting itself. This array of school-related factors may lead to a higher degree of detection, referral, and diagnosis and, therefore, a significant increase in prevalence rates of autism/ASD among school-age children compared with preschool-age children.

One limitation of this study is that the data did not allow for separation of "school beginners" (6- to 7-year-olds) for comparison with the rest of the school-age children to determine whether school age, in general, or school-beginning age, in particular, accounts for the increase in prevalence rates of autism/ASD among 6- to 16-year-old children. Further
Fig. 1 Increase in prevalence rates of autism/ASD among boys and girls in 2014 and 2016

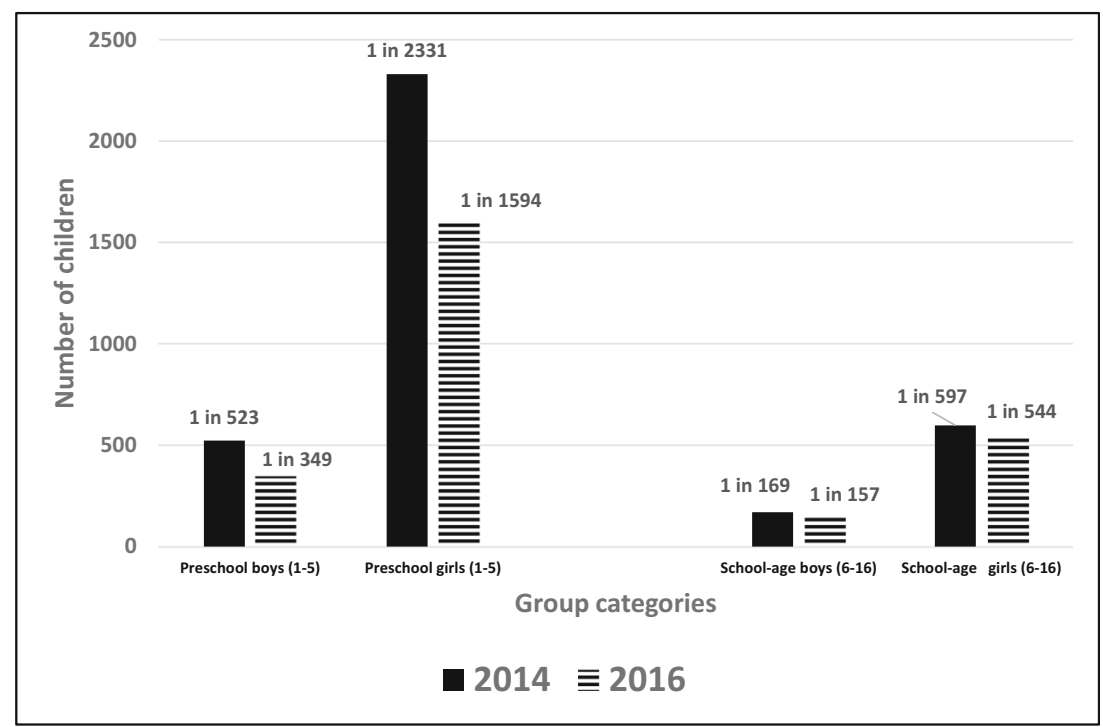


research is needed for a more detailed study of subgroups among school-age children. More research is also needed with regard to gender-related issues in the assessment of females. Nevertheless, the findings of this study of the prevalence of autism/ASD among preschool (1 to 5 years old) and schoolage (6-16 years old) Norwegian children are informative for international researchers and essential for policymakers in the health, social, and educational sectors. Planning for appropriate services for treatment, training, and teaching that will serve an increased number of children with autism/ASD at school age is essential. Reliable prevalence rates for children at different age groups can make this type of planning easier, ensuring proper accommodations for and provision of equitable services for children with autism/ASD.

There is a substantial amount of research (Odom et al. 2013; Klintwall and Eikeseth 2014; Koegel et al. 2014; Wong et al., 2015, 2015; Steinbrenner et al. 2020) detailing 28 evidencebased practices in the autism field (e.g., Discrete Trial Teaching, Pivotal Response Training, Video Modeling, Cognitive Behavioral Intervention, PECS and Social Narratives). Implementing evidence-based practices can make a difference in the life of children with autism/ASD. Thus, the findings of this study also show the clear need for national initiatives in Norway focused on improving ASD-related competence among teachers, preschool teachers, special education teachers, educational psychologists, counselors, speech pathologists, and school leaders. For this purpose, we suggest designing credential programs or specially designed certification courses at universities, focusing on evidence-based practices and recent research findings in the field of ASD for these professionals who work directly with children with autism/ASD.

Such improvements in capacity-building in Norway's kindergartens and schools are of the utmost importance for enhancing the quality of children's treatment, as well as training, teaching, and learning conditions.

Funding Information Open Access funding provided by University of Oslo (incl Oslo University Hospital). This research was funded by Research Support Grant 21-02-2018, Department of Education, University of Oslo.

\section{Compliance with Ethical Standards}

Conflict of Interest The authors declare that they have no conflict of interest.

Human and Animal Rights and Informed Consent This article does not contain any studies with human participants or animals performed by any of the authors.

Open Access This article is licensed under a Creative Commons Attribution 4.0 International License, which permits use, sharing, adaptation, distribution and reproduction in any medium or format, as long as you give appropriate credit to the original author(s) and the source, provide a link to the Creative Commons licence, and indicate if changes were made. The images or other third party material in this article are included in the article's Creative Commons licence, unless indicated otherwise in a credit line to the material. If material is not included in the article's Creative Commons licence and your intended use is not permitted by statutory regulation or exceeds the permitted use, you will need to obtain permission directly from the copyright holder. To view a copy of this licence, visit http://creativecommons.org/licenses/by/4.0/.

\section{References}

Baird, G., Simonoff, E., Pickles, A., Chandler, S., Loucas, T., Meldrum, D., \& Charman, T. (2006). Prevalence of disorders of the autism spectrum in a population cohort of children in South Thames: the Special Needs And Autism Project (SNAP). Lancet, 368, 210-215.

Baron-Cohen, S., Scott, F. J., Allison, C., Williams, J., Bolton, P., Matthews, F. E., \& Brayne, C. (2009). Prevalence of autism-spectrum conditions: UK school-based population study. The British Journal of Psychiatry, 194, 500-509. https://doi.org/10.1192/bjp.bp.108.059345.

Blumberg, S. J., Bramlett, M. D., Kogan, M.D., Schieve, L.A., Jones, J. R., \& Lu, M. C. (2013). Changes in prevalence of parent-reported autism spectrum disorder in school-aged U.S. children: 2007 to 2011-2012 (National Health Statistics Reports No. 65). Hyattsville, MD: National Center for Health Statistics.

Cardinal, D., \& Fraumeni-McBride, J. (2017). Increase in rate of autism likely a factor of definition. Report presented at the Inaugural Disability Summit. Orange, CA: Chapman University, Thompson Policy Institute.

Baio, J., Wiggins, L., Christensen, D. L., Maenner, M. J., Daniels, J., Warren, Z., Kurzius-Spencer, M., Zahorodny, W., Robinson Rosenberg, C., White, T., Durkin, M. S., Imm, P., Nikolaou, L., Yeargin-Allsopp, M., Lee, L. C., Harrington, R., Lopez, M., Fitzgerald, R. T., Hewitt, A., Pettygrove, S., ... Dowling, N. F. (2018). Prevalence of autism spectrum disorder among children aged 8 years - autism and developmental disabilities monitoring network, 11 sites, United States, 2014. Morbidity and mortality weekly report. Surveillance summaries (Washington, D.C.: 2002), 67(6), 1-23. https://doi.org/10.15585/mmwr.ss6706a1.

Christensen, D. L., Braun, K., Baio, J., Bilder, D., Charles, J., Constantino, J. N., Daniels, J., Durkin, M. S., Fitzgerald, R. T., Kurzius-Spencer, M., Lee, L. C., Pettygrove, S., Robinson, C., Schulz, E., Wells, C., Wingate, M. S., Zahorodny, W., \& Yeargin-Allsopp, M. (2018). Prevalence and characteristics of autism spectrum disorder among children aged 8 years - autism and developmental disabilities monitoring network, 11 sites, United States, 2012. Morbidity and mortality weekly report. Surveillance summaries (Washington, D.C. : 2002), 65(13), 1-23. https://doi.org/10.15585/mmwr.ss6513a1.

Davidovitch, M., Hemo, B., Manning-Courtney, P., \& Fombonne, E. (2013). Prevalence and incidence of autism spectrum disorder in an Israeli population. Journal of Autism and Developmental Disorders, 43, 785-793. https://doi.org/10.1007/s10803-012-1611-z.

Eikeseth, S., Smith, T., Jahr, E., \& Eldevik, S. (2007). Outcome for children with autism who began intensive behavioral treatment between ages 4 and 7. A comparison controlled study. Behavior Modification. Vol. 31 Nr.3, 264-278.

Eldevik, S., Hastings, R. P., Hughes, J. C., Jahr, E., Eikeseth, S., \& Cross, S. (2009). Meta-analysis of early intensive behavioral intervention for children with autism. Journal of Clinical Child Adolescent Psychology., 38(3), 439-450. https://doi.org/10.1080/15374410902851739.

Elsabbagh, M., Divan, G., Koh, Y.-J., Kim, Y. S., Kauchali, S., Marcín, C., Montiel-Nava, C., Patel, V., Paula, C. S., Wang, C., Yasamy, M. T., \& Fombonne, E. (2012). Global prevalence of autism and other pervasive developmental disorders. Autism Research, 5(3), 160-179.

Gilberg, C., Cederlund, M., Lamberg, K., \& Zeijlon, L. (2006). Brief report: "The autism epidemic." The registered prevalence of autism 
in a Swedish urban area. Journal of Autism and Developmental Disorders, 36(3), 429-435.

Green, H., McGinnity, A., Meltzer, H., Ford, T., \& Goodman, R. (2004). Mental health of children and young people in Great Britain. Gosport, UK: Palgrave Macmillan/National Statistics.

Gundersen, T. \& Hem K.-G, (2005). Brukerundersøkelse blant personer med diagnose innen autismespekteret. Erfaringer med Autismenettverket [User survey among people with a diagnosis within the autism spectrum. Experiences with Autism Network]. 09-15 STF78 A054504.

Honda, H., Shimizu, Y., \& Rutter, M. (2005). No effect of MMR withdrawal on the incidence of autism: a total population study. Journal of Child Psychology and Psychiatry, 46, 572-579.

Idring, S., Rai, D., Dal, H., Dalman, C., Sturm, H., Zander, E., Lee, BK., Serlachius, E., \& Magnusson, C. (2012). Autism spectrum disorders in the Stockholm Youth Cohort: design, prevalence and validity. PLoS ONE. 7(7). e41280. doi:https://doi.org/10.1371/journal.pone.0041280.

Isaksen, J., Diseth, T. H., Schjølberg, S., \& Skjeldal, O. H. (2012). Observed prevalence of autism spectrum disorders in two Norwegian counties. European Journal of Paediatric Neurology, 16(6), 592-598.

Kawamura, Y., Takahashi, O., \& Ishii, T. (2008). Reevaluating the incidence of pervasive developmental disorders: impact of elevated rates of detection through implementation of an integrated system of screening in Toyota, Japan. Psychiatry and Clinical Neuroscience, 62, 152-159.

Klintwall, L., \& Eikeseth, S. (2014). Early and intensive behavioral intervention (EIBI) in autism. In V. B. Patel, V. R. Preedy, \& C. R. Martin (Eds.), Comprehensive guide to autism. New York: Springer-Verlag.

Koegel, L. K., Koegel, R. L., Ashbaugh, K., \& Bradshaw, J. (2014). The importance of early identification for children with or at risk for autism spectrum disorder. International Journal of SpeechLanguage Pathology, 16(1), 50-56.

Lai, D.-C., Tseng, Y.-C., Hou, Y.-M., \& Guo, H.-R. (2012). Gender and geographic differences in the prevalence of autism spectrum disorders in children: analysis of data from the national disability registry of Taiwan. Research in Developmental Disabilities., 33, 909-915.

Loomes, R., Hull, L., \& Mandy, W.P.L. (2017). What is the male-tofemale ratio in autism spectrum disorder? A systematic review and meta-analysis. Journal of the American Academy of Child \& Adolescent Psychiatry. Vol. 56, nr. 6, 466-474.

Maenner, M. J., Shaw, K. A., Baio, J., EdS1, Washington, A., Patrick, M., DiRienzo, M., Christensen, D. L., Wiggins, L. D., Pettygrove, S., Andrews, J. G., Lopez, M., Hudson, A., Baroud, T., Schwenk, Y., White, T., Rosenberg, C. R., Lee, L. C., Harrington, R. A., Huston, M., ... Dietz, P. M. (2020). Prevalence of autism spectrum disorder among children aged 8 years - Autism and Developmental Disabilities Monitoring Network, 11 sites, United States, 2016. Morbidity and mortality weekly report. Surveillance summaries (Washington, D.C. : 2002), 69(4), 1-12. https://doi.org/10.15585/ mmwr.ss6904a1

Matson, J. L., \& Kozlowski, A. M. (2011). The increasing prevalence of autism spectrum disorders. Research in Autism Spectrum Disorders, $5,418-424$

National Autistic Society. (2018). What is autism? Retrieved from http:// www.autism.org.uk/about/what-is.aspx

Statistics Norway (2013). Retrieved from http://www.ssb.no

Statistics Norway (2014). Retrieved from http://www.ssb.no

Statistics Norway (2015). Retrieved from http://www.ssb.no

Statistics Norway (2016). Retrieved from http://www.ssb.no

Statistics Norway (2017). Retrieved from http://www.ssb.no

Ouellette-Kuntz, H., Coo, H., \& Gorski, D. (2012). Findings from the National Epidemiologic Database for the Study of Autism in Canada (NEDSAC). Changes in the prevalence of autism spectrum disorders in Newfoundland and Labrador, Prince Edward Island, and
Southeastern Ontario. Kingston, Ontario: NEDSAC, Queen's University.

Özerk, K. (2016). The issue of prevalence of autism/ASD. International Electronic Journal of Elementary Education, 9(2), 263-306.

Parner, E. T., Schendel, D. E., \& Thorsen, P. (2008). Autism prevalence trends over time in Denmark: changes in prevalence and age at diagnosis. Archives of Pediatrics and Adolescent Medicine, 162(12), 1150-1156.

Roelfsema, M. T., Hoekstra, R. A., Allison, C., Wheelwright, S., Brayne, C., Matthews, F. E., \& Baron Cohen, S. (2012). Are autism spectrum conditions more prevalent in an information-technology region? A school-based study of three regions in the Netherlands. Journal of Autism and Developmental Disorders, 42(5), 734-739.

Sandin, S., Lichtenstein, P., Kuja-Halkola, R., Larsson, H., Hultman, C. M., \& Reichenberg, A. (2014). The familial risk of autism. Journal of the American Medical Association (JAMA), 311(17), 770-1777. https://doi.org/10.1001/jama.2014.4144.

Steinbrenner, J. R., Hume, K., Odom, S. L., Morin, K. L., Nowell, S. W., Tomaszewski, B., et al. (2020). Evidence-based practices for children, youth, and young adults with autism. Chapel Hill: The University of North Carolina, Frank Porter Graham Child Development Institute, National Clearinghouse on Autism Evidence and Practice Review Team.

Stoltenberg, C., Schjølberg, S., Bresnahan, M., Hornig, M., Hirtz, D., Dahl, C., Lie, K. K., Reichborn-Kjennerud, T., Schreuder, P., Alsaker, E., Øyen, A. S., Magnus, P., Surén, P., Susser, E., Lipkin, W. I., \& ABC Study Group. (2010). The Autism Birth Cohort: a paradigm for geneenvironment-timing research. Molecular Psychiatry, 15(7), 676-680. https://doi.org/10.1038/mp.2009.143.

Surén, P., Bakken, I. J., Aase, H., Chin, R., Gunnes, N., Lie, K. K., Magnus, P., Reichborn-Kjennerud, T., Schjølberg, S., Øyen, A. S., \& Stoltenberg, C. (2012). Autism spectrum disorder, ADHD, epilepsy, and cerebral palsy in Norwegian children. Pediatrics, 130(1), e152-e158. https://doi.org/10.1542/peds.2011-3217.

Warren, Z., McPheeters, M.L., Sathe, N., Foss-Feig, J. H., Glasser, A., \& Veenstra-Vander Weele, J. (2011). A systematic review of early intensive intervention for autism spectrum disorders. Pediatrics Vol. 127 nr 5, e1303-e1311. DOI: https://doi.org/10.1542/peds.2011-0426.

Williams, E., Thomas, K., Sidebotham, H., \& Emond, A. (2008). Prevalence and characteristics of autistic spectrum disorders in the ALSPAC cohort. Developmental Medicine and Child Neurology, 50(9), 672-677.

Wong, C., Odom, S. L., Hume, K. A., Cox, A. W., Fettig, A., Kucharczyk, S., Brock, M. E., Plavnick, J. B., Fleury, V. P., \& Schultz, T. R. (2015). Evidence-based practices for children, youth, and young adults with autism spectrum disorder: a comprehensive review. Journal of Autism and Developmental Disorders, 45(7), 1951-1966. https://doi.org/10.1007/s10803-014-2351-z.

Zablotsky, B., Black, L. I., Maenner, M. J., Schieve, L. A., \& Blumberg, S. J. (2015). Estimated prevalence of autism and other developmental disabilities following questionnaire changes in the 2014 National Health Interview Survey. National Health Statistics Reports, 87, 1-20.

Publisher's Note Springer Nature remains neutral with regard to jurisdictional claims in published maps and institutional affiliations.

Kamil Özerk, PhD. Professor of Education, Faculty of Educational Sciences, Department of Education, University of Oslo, Norway.

Dr. Donald Cardinal is Professor of Education in the Attallah College of Educational Studies at Chapman University, Orange, CA, where he has worked since 1987. Previously, Dr. Cardinal served as dean of the College of Educational Studies from 2002-2015. Don currently is director of the Thompson Policy Institute on Disability and Autism. 